\title{
ITINERÁRIO PERCORRIDO PELAS MULHERES NA DESCOBERTA DO CÂNCER ${ }^{\mathrm{a}}$
}

\author{
The journey experienced by women \\ through a cancer diagnosis \\ Camino recorrido por las mujeres en la \\ descubierta del cáncer
}

Sonia Silva Marcon ${ }^{2}$

\section{RESUMO}

Este estudo se propõe a desvelar o itinerário vivenciado pelas mulheres no processo de descoberta do diagnóstico de câncer. Como estratégia teórico-metodológica, foram utilizados o Interacionismo Simbólico e a Grounded Theory. Foram informantes do estudo 20 indivíduos - 10 mulheres portadoras de câncer e seus respectivos familiares significantes. Os resultados mostram desde o momento em que elas vivenciam as primeiras percepções sobre a alteração fisiológica em seu corpo, passando pela busca de ajuda profissional, até o recebimento do diagnóstico de câncer. 0 itinerário apresentado permite conhecer aspectos da realidade experienciada anteriormente ao recebimento do diagnóstico e ressalta a importância de os profissionais valorizarem mais as queixas das pessoas que os procuram, percebendo que se esta procura aconteceu é porque a pessoa está preocupada. Esta atitude pode favorecer a identificação precoce do problema e, por conseguinte, garantir melhor prognóstico e qualidade de vida.

Palavras-chave: Neoplasias. Mulheres. Família. Diagnóstico. Enfermagem Oncológica.

\begin{abstract}
This study intends to reveal the journey experienced by women in the process of facing a cancer diagnosis. Symbolic Interactionism and Grounded Theory were used as theoreticalmethodological strategies. Twenty individuals took part in the study - 10 female cancer bearers and their respective significant others. The results are described starting from the moment they experience their first perceptions of the physiologic changes in their bodies, through the search for professional help, to the acknowledgement of a cancer diagnosis. The given itinerary presents aspects of the patients' reality prior to the diagnosis, and emphasizes the importance of professionals giving more credence to the complaints of patients who seek them - if the patient made an appointment, it is because that person is concerned. This attitude can promote the early identification of the problem, and consequently guarantee a better prognosis and quality of life.
\end{abstract}

Keywords: Neoplasms. Women. Family. Diagnosis. Oncology nursing.

\section{Resumen}

Este estudio propone revelar el camino vivido por las mujeres en el proceso de descubierta del diagnóstico de cáncer. Como estrategia teórico-metodológica fueron utilizados el Interaccionismo Simbólico y la Grounded Theory. Fueron investigados durante el estudio 20 individuos - 10 mujeres portadoras de cáncer y sus respectivos familiares próximos. Los resultados muestran desde el momento en que ellas notan las primeras diferencias sobre la alteración fisiológica en su cuerpo, pasando por la búsqueda de ayuda profesional hasta el recibimiento del diagnóstico de cáncer. El camino presentado permite conocer aspectos de la realidad vivida anteriormente al recibimiento del diagnóstico y resalta la importancia de que los profesionales valoren más las quejas de las personas que los buscan, percibiendo que si esta búsqueda ocurrió es porque la persona está preocupada. Esta actitud puede facilitar la identificación precoz del problema y, por consiguiente, garantizar un mejor pronóstico y una mejor calidad de vida.

Palabras Clave: Neoplasias. Mujeres. Familia. Diagnóstico. Enfermería oncológica.

\footnotetext{
'Mestre em Enfermagem. Professora do Departamento de Enfermagem da Universidade Estadual de Maringá. Integrante do NEPAAF

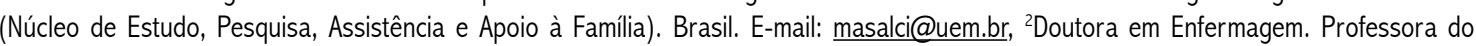
Departamento de Enfermagem da Universidade Estadual de Maringá. Coordenadora do Programa de pós-graduação em Mestrado em Enfermagem da Universidade Estadual de Maringá. Coordenadora do NEPAAF. Brasil. E-mail: soniasilva.marcon@gmail.com
} 


\section{INTRODUCÃO}

Sendo o câncer uma doença de características diferenciadas de outras doenças crônicas, em virtude de sua fisiopatologia que pode provocar deformidades, dor e mutilações, ele traz em seu bojo um estigma que causa forte impacto psicológico sobre o indivíduo, produzindo sentimentos como medo, ansiedade, angústia, dúvidas, raiva e sofrimento emocional desde 0 momento de seu diagnóstico. ${ }^{1: 2}$

Assim, considerando-se que o câncer tem como características a longa permanência, a possibilidade de recidiva e necessidade de intervenção, às vezes é natural que a sua ocorrência altere o contexto familiar, visto que expõe todos os membros a uma maior vulnerabilidade com relação às perdas, entre elas as de "saúde, bem-estar, financeira, equilíbrio físico, mental e emocional". ${ }^{3}$ Estas características ressaltam o papel da família diante da responsabilidade de exercer o cuidado familiar a seu membro doente ${ }^{4}$.

Neste sentido, ressalta-se que todas as doenças possuem um fator psicológico associado, e fatores emocionais desencadeiam uma série de alterações do corpo, através dos nervos e hormônios, precipitando o início, recorrência ou agravamento de sintomas. ${ }^{5}$ Assim, apesar da alta incidência de cura quando diagnosticado precocemente, o câncer ainda é uma doença que traz embutida em si sentimentos de morte iminente, preconceitos e discriminação social, ${ }^{6}$ trazendo transtornos biopsicossociais aos pacientes por ele afetados, conduzindo-os a uma readaptação das suas vivências intrapsíquicas, que provocam mutilações físicas e alterações psicológicas irreversíveis, deixando marcas e provocando mudanças no cotidiano familiar, social, profissional e nos relacionamentos de amizade.

Neste sentido, o enfrentamento do câncer traz muitas dificuldades, tanto pela doença em si como por seu tratamento, pois ambos envolvem aspectos físicos e emocionais. No entanto, a descoberta dessa patologia muitas vezes é retardada, por envolver etapas extremamente significativas que precedem 0 seu diagnóstico. Esse itinerário fica obscuro aos olhos de muitos profissionais, que iniciam o processo de cuidar a partir apenas da comprovação da doença por exames laboratoriais e outros métodos.

Ademais, no momento em que a mulher se depara com o diagnóstico de câncer, seu modo de vida e suas relações interpessoais passam a ser objeto de reflexão e questionamentos. Considerando-se que tal processo tem início com a descoberta da doença, torna-se importante atentar para esse momento e realizar uma análise acerca desse tipo de experiência. Trata-se de uma etapa peculiar da vida, em que a mulher passa a assumir o papel de doente, além de todos aqueles anteriormente desempenhados por ela.

Assim, considerando-se que a valorização das etapas precedentes ao diagnóstico pode influenciar diretamente 0 tratamento e, consequentemente, o prognóstico da doença, propusemo-nos a desvelar o itinerário vivenciado pelas mulheres no processo de descoberta do diagnóstico de câncer.

\section{PERCURSO METODOLÓGICO}

0 estudo é do tipo exploratório de natureza qualitativa, e adotou o Interacionismo Simbólico (IS), como referencial teórico e a Grounded Theory, como referencial metodológico.

0 estudo foi realizado no município de Maringá - PR, no período de março a novembro de 2005. Os dados foram coletados com 20 informantes - 10 mulheres portadoras de câncer e seus 10 respectivos familiares significantes constituindo-se três grupos amostrais. 0 primeiro se constituiu de 5 mulheres que enfrentavam o tratamento contra o câncer pela primeira vez; o segundo, por três mulheres que estavam em tratamento por metástase; e o terceiro, por três mulheres que tinham passado por tratamento havia mais de cinco anos. Uma das mulheres integrou os grupos 1 e 2. Na composição dos grupos, foram respeitados os critérios de amostragem e saturação teórica. ${ }^{7}$

As mulheres do estudo tinham idade de 27 a 50 anos, com níveis de escolaridade e social diversos, e, embora não nos importasse a localização da doença, mas sim o significado atribuído a ela, houve predomínio do câncer de mama (oito casos). Como familiares entrevistados, tivemos quatro filhas, duas irmãs, dois esposos, uma mãe e uma prima.

A localização das mulheres ocorreu a partir dos registros em uma clínica de radioterapia. 0 primeiro contato para solicitação de participação no estudo foi por telefone ou na própria clínica. A partir daí, realizaram-se as entrevistas abertas, no domićlio, em dia e horário pré-agendados.

0 projeto de pesquisa foi aprovado pelo Comitê Permanente de Ética em Pesquisa com Seres Humanos da Universidade Estadual de Maringá (Parecer n. 045/2005). Para assegurar 0 anonimato das informantes, utilizamos nomes fictícios.

A análise dos dados permitiu a identificação do fenômeno central: "ENFRENTANDO 0 CÂNCER EM FAMÍLIA", constituído por três processos (Descobrindo a doença; Percebendo mudanças após o diagnóstico de câncer; Tendo que conviver com o câncer), e nesta comunicação apresentamos o primeiro processo.

\section{APRESENTANDO E DISCUTINDO OS RESULTADOS}

Antes de vivenciar os infortúnios de uma doença, a pessoa passa por etapas que precedem o conhecimento de seu diagnóstico, e, dependendo do significado de doença que a pessoa desenvolveu ao longo da vida, poderá agir de maneira rápida no sentido de elucidar suas dúvidas, culminando ou não com a descoberta da doença ou com o retardamento desse processo.

As vivências experienciadas durante o processo DESCOBRINDO A DOENÇA deram origem às categorias "Vivenciando as primeiras percepções", "Buscando ajuda profissional" e "Recebendo o diagnóstico de câncer". 


\section{Vivenciando as primeiras percepções}

Quando a mulher percebe alterações em seu corpo, automaticamente faz suposições, sendo esse momento vivenciado de modo muito singular. Essa é uma etapa importante, pois, para vários tipos de câncer, a atitude tomada nesta ocasião determinará, em grande parte, o sucesso dos tratamentos. Isso porque a maioria dos tipos de câncer tem uma característica silenciosa, e quanto antes a doença for detectada e diagnosticada, maiores as chances de um tratamento bem-sucedido. ${ }^{3}$

0 processo de descoberta da doença tem início quando a mulher detecta que algo se encontra modificado em seu corpo. No relato de sua experiência, a maioria das mulheres revelou ter descober to o câncer de maneira inusitada, por acaso, ou seja, sem que elas estivessem desconfiando de algum problema de saúde.

Eu estava amamentando minha filha e senti um caroço... (Ana Maria).

Ah! Eu terminei de limpar a casa, era um dia bem quente, e quando eu terminei, deitei no chão e não sei como, eu peguei efiz assim [deslizou a mão em cima das mamas], porque eu nunca fazia autoexame das mamas e do jeito que eu estava, o seio espalhou e eu senti um caroço no meu seio... (Camila).

Às vezes este processo tem início a partir da percepção quanto ao aparecimento de um sintoma físico, como mostra a fala seguinte:

Bom... eu nunca tinha feito preventivo. Sabia que precisava, mas foi por ignorância mesmo; só que eu não sentia nada e de repente começou sangrar, sangrava muito, aí eu fui para o pronto-socorro... (Regiane).

A descoberta da modificação em seu corpo a partir da realização de autoexame das mamas, é rara, mas foi o que aconteceu com Maria Santa:

Bom, toda a vida eu fiz os exames, toque, sempre apalpando, e sempre a partir da última gestação. Eu tava com trinta e cinco anos já comecei fazer mamografia. Toda a vida eu morria de medo disso daí, morro de medo disso [do câncer].

Ante a percepção da alteração em seu corpo, a mulher pode ou não vislumbrar a possibilidade de estar com câncer, $\mathrm{e}$ assim passa a fazer suposição a respeito dessa nova realidade. Quando não faz associação da alteração com algum problema grave, ela normalmente não se preocupa, mas quando pensa em uma doença mais séria, o temor e a angústia passam a fazer parte do seu viver.
Às vezes, o pensar ou não na possibilidade de uma doença mais grave é determinado pela idade das pessoas: "A gente não imagina que com essa idade [27 anos] vá ter uma doença assim" (Tânia).

É comum, por exemplo, as mulheres mais velhas, em um primeiro momento, fazerem associação das alterações com as mudanças que são próprias de sua faixa etária.

[...] quando eu estava em casa com sangramento, penseique poderia ser conseqüência da menopausa, porque tem gente que fala que sangra muito. Pensei: "ah, eu vou ter que ir ao médico para ver, para fazer tratamento" (Regiane).

Outro aspecto ressaltado pelas depoentes refere-se ao histórico familiar, ou seja, se em sua família nunca houve casos de câncer, dificilmente ela pensará nesta possibilidade em um primeiro momento:

Eu não me preocupei, porque como na familia nunca tinha tido nenhum caso, e eu sempre ouvi falar que só... principalmente é uma coisa hereditária. Daí eu fui deixando. Só que em março eu vi que realmente era mais sério do que se pensa (Alessandra).

Nesse período de dúvida, é comum a mulher compartilhar suas dúvidas e experiências com sua rede social mais próxima, caracterizada tanto por alguns integrantes da família como pelos amigos. A família, por sua vez, participa transmitindo sentimentos positivos, mas angustia-se com o desalento de seu ente querido, pois percebe que este traz em si sentimentos negativos quanto ao futuro.

[...] todo mundo esperava que fosse uma coisa boa. Mas ela estava bem apreensiva. Sabe quando a pessoa já estava esperando que fosse dar alguma coisa? Ela estava totalmente abalada antes de ir buscar o resultado do exame (irmã de Camila).

Os familiares também se envolvem nesse processo, como no caso do marido que se mostrou interessado em descobrir a causa do nódulo, orientando a esposa a procurar o médico.

Eu não fiquei apavorada e nem preocupada, porque nem passava pela minha cabeça um câncer, nada, nada. Na hora eu só olhei, comentei com meu marido e ele falou: quando você for ao médico, você mostra (Mônica).

Em outro depoimento, notamos que quando a mulher está amamentando e, além disso, encontra-se em uma idade em que é pouco comum o câncer de mama, as pessoas costumam não correlacionar a alteração percebida na mama com a 
possibilidade de uma doença maligna, o que contribui para que o diagnóstico seja realizado tardiamente.

Eu conversei com minha tia que trabalha no posto... e ela falou... "Ana Maria, é leite, porque você está amamentando...", minha filha tinha dois, três meses, daí eu falei: então tá bom... (Ana Maria).

A redescoberta do câncer, ou seja, a identificação de uma metástase, pode seguir outro caminho. Ana Maria afirma ter recebido um prenúncio enquanto orava:

Na verdade eu já sabia que ia voltar, porque Deus já tinha falado para mim que a doença iria voltar, e ninguém acreditava... Daí um dia eu estava na igreja, e o pastor estava pregando, e ele começou a falar que ia fazer um congresso em 2006. Veio na minha cabeça assim, "Será que até 2006 eu estou viva", conversando com Deus mesmo. Aí falei: "Ah, não vou pensar nisso". Mas Deus falou comigo: "A sua enfermidade vai voltar, mas você não faça quimioterapia, só creia em mim", e foi assim. Eu não comentei com ninguém, e de repente começou aparecer caroço no meu corpo, nas minhas costas, no peito, no meu braço, no meu pescoço... (Ana Maria).

Assim, o subprocesso Vivenciando as primeiras percepções permite saber que na maioria das vezes é a própria mulher que identifica alteração em seu corpo, ou pelo menos percebe que algo não se encontra mais normal. Isto é compreensível, já que são elas as principais responsáveis pelo seu autocuidado e também pelo cuidado aos membros familiares. ${ }^{8}$ Em todas as sociedades do mundo, são elas que desenvolvem cuidados principalmente relacionados ao corpo e à alimentação, além de ser o elemento que cuida dos outros durante eventos especiais da vida?.

Esses papéis que as mulheres vêm assumindo ao longo dos tempos é consequência do processo de socialização educativa e social que ocorre dentro da própria família, e que valoriza a divisão sexual do trabalho. ${ }^{10}$

\section{Buscando ajuda profissional}

A angústia ante a possibilidade de estar com câncer, ao mesmo tempo em que faz a mulher sentir-se derrotada diante de si mesma, também suscita no âmago de seu ser forças para buscar esclarecimento do problema junto a um profissional de saúde. É importante ressaltar que todas as mulheres que fizeram parte deste estudo procuraram o médico como primeira opção, ou seja, nenhuma delas fez referência à procura de métodos populares de cuidado à saúde.

No momento em que buscam ajuda profissional, todas as mulheres afirmaram que, mais cedo ou mais tarde, tinham procurado o médico para esclarecer o problema. Muitas vezes as respostas não foram imediatas, acontecendo um retardo no diagnóstico, às vezes até por negligência do profissional, ao não valorizar as queixas e a percepção da mulher.

Não obstante, todas elas demonstraram possuir atitudes de reivindicar seus direitos com vistas a uma resposta concreta sobre o problema, sendo insistentes, perseverantes e responsáveis e buscando outros profissionais.

0 sentimento de insegurança diante da possibilidade de estar com neoplasia desencadeia a atitude de a mulher negar a si mesma a suspeita de ter uma doença grave; contudo, é possível perceber que ela já está cônscia de que esta negação está associada ao medo do diagnóstico. Sendo assim, em seu íntimo, ela reconhece sua responsabilidade de procurar auxilio médico após orientação.

Na hora... como uma amiga minha já tinha tido, eu perguntei a ela como era; aí ela passou a mão, falou: "Está uma coisinha mínima, pode ser um cisto". Só que ele estava duro, não se mexia. Ela falou: "Ele não se move, é bom você ir ao médico" (Alessandra).

Algumas mulheres, no entanto, ao perceberem alteração em seu corpo, enfrentam a suspeita e procuram o médico rapidamente para esclarecer suas dúvidas, como no caso de Nathália: "... apareceu um caroço no meu seio e eu fui ao médico". Não obstante, pudemos constatar, também, que outras mulheres, apesar de sentirem em si modificações significativas, antes de procurar ajuda médica, permaneceram por um tempo passivamente aguardando a solução do problema.

[...] notei um caroço, aí eu dei um tempo, dois meses. Falei: "Ah, deve ser a menstruação que está para vir e pode inchar a mama um pouco". Aí eu vi que não era e fui ao médico (Maria Santa).

0 fato de as mulheres demorarem a procurar ajuda profissional pode estar relacionado aos temores decorrentes das possibilidades de mutilações e danos dos tratamentos, bem como a outras representações sobre a causa da doença. ${ }^{11}$ Nestes casos, quando a solução da alteração em seu corpo não chega no prazo mentalmente estabelecido, as mulheres são unânimes em tomar uma atitude no sentido de buscar um profissional médico para sanar suas dúvidas.

No entanto, esta atitude nem sempre é eficaz, pois o médico também pode não correlacionar a alteração com a possibilidade de ser uma doença maligna, contribuindo para que o diagnóstico de câncer seja tardio.

[...] eu amamentei ela uns seis meses, normal. $E$ aquele caroço estava muito grande. Aí voltei a trabalhar e mostrei para o meu médico, ele falou: "Não, Ana Maria, realmente é leite" (Ana Maria). 
Mesmo deparando-se com um profissional que não relaciona a presença do nódulo com uma doença, ao perceber o constante e progressivo aumento do problema, esta mulher, insatisfeita com o diagnóstico, continua sua caminhada à procura de outras opiniões.

[...] nisso minha filha fez um ano, fez quase um ano e aquele negócio crescendo. Aí eu peguei, via que não sumia, procurei um outro médico (Ana Maria).

Não obstante, mais uma vez a atitude do novo profissional médico também foi percebida como negligente, de forma que, em seu relato, Ana Maria demonstra toda a sua indignação, pois, apesar de ela expor ao médico que sentia mudanças em seu corpo, esses fatos foram totalmente ignorados:

[...] o médico apalpou e falou que não precisava me preocupar que não era câncer, só que tinha que tirar, porque era duro, e falou: "Só que não tenha pressa, Ana Maria, não se preocupe...". Não pediu nem um tipo de exame, ele não pediu nada, e ficou como não era nada, e eu também não fui atrás e demorei para voltar... (Ana Maria).

Casos como esses revelam quanto os profissionais de saúde, em especial os médicos, precisam valorizar mais as percepções das pessoas, e quanto se fazem necessários alguns "cuidados" nas ocasiões em que forem transmitir o diagnóstico de uma doença grave, pois a veracidade do fato deve ser exposta, porém de forma adequada. Nestas ocasiões, as pessoas precisam compreender a real situação e ao mesmo tempo serem esclarecidas sobre as possibilidades de tratamento.

É observado que alguns profissionais, além de estarem despreparados para fazer um diagnóstico de câncer, acabam por negligenciar o fato diante de uma alteração real e significante no corpo da mulher.

Fui lá no $\operatorname{Dr}\left(^{*}\right)$, ele fez mamografia e ultrassom e falou que não era nada, porque podia sumir com o tempo, que era pequeno e tal... Aí passou, e eu continuei trabalhando, e como a gente não entende nada... Passou um tempo, como aumentou um pouquinho, eu voltei e ele falou que eu tinha colocado na cabeça, que era assim mesmo (Nathália).

Apesar de os médicos afirmarem que o problema não era grave, observa-se nas falas que a mulher pressentia em si algo de ruim e, por esta razão, persistiu em sua peregrinação em busca de respostas mais convincentes:

Aí passou um pouco, falei "Ah! Vou procurar uma segunda opinião". Fui com o Dr (?), mas eu falei para ele que eu tinha quase certeza que era o câncer, ele falou: "Não, não é assim, vamos fazer os exames". Fiz ultrassom e mamografia de novo. Aí ele falou que queria fazer punção; fez e veio o resultado da biópsia... era câncer (Nathália).

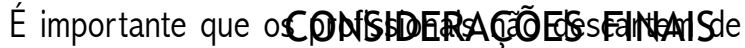
imediato as possibilidades de malignidade, uma vez que 0 exame clínico e os de imagem pontuam alterações e o resultado final só pode ser determinado pelo anatomopatológico, depois da retirada de algumas células do local.

\section{Recebendo o diagnóstico de câncer}

A realização da biópsia representa o ápice do caminho percorrido em direção à definição do diagnóstico. Por algum tempo, a mulher canaliza suas forças nessa direção, e após sua realização, ela entra em um estágio de letargia, pois nada pode ser feito antes de chegar o resultado da biópsia, o que demora mais ou menos 20 dias. Durante esse tempo, a mulher experiencia momentos de esperança e desesperança, marcados principalmente por ansiedade.

Os depoimentos revelaram que o momento em que receberam o diagnóstico de câncer foi bastante peculiar para a maioria das mulheres. Reagindo a essa situação, experienciam sentimentos diversos, que provocam forte impacto emocional - "Puxa... o baque foi muito grande..." (Mônica) - acompanhados de tristeza, frustração, angústia e dificuldade de introjeção, aceitação e apreensão do que significa perceber-se uma portadora de câncer.

Parece que o meu chão saiu, porque a gente não imagina que com essa idade [27 anos] vá ter uma doença assim. Fiquei arrasada [...] primeiro você vê um buraco, uma coisa assim que você acha que vai morrer (Tânia).

Esses sentimentos também são experienciados pelos familiares

[...] a decepção, a tristeza, tudo foi igual como se fosse ela, porque irmão quando um está sofrendo o outro sofre igual. Eu senti tristeza, medo de perder, falta de esperança... (irmã de Nair).

Às vezes, a mulher também se depara com o sentimento de revolta, pois estar com câncer é uma condição difícil de ser compreendida imediatamente pela pessoa:

No começo você pergunta: "Deus, o que eu estou fazendo aqui?". Daí você pergunta: "Deus, por que isso comigo? Por que foi acontecer comigo? (Mônica).

Os relatos também apontam a importância de a pessoa estar com um membro da família ao receber o diagnóstico de 
câncer, pois a simples presença de outra pessoa pode funcionar como suporte emocional, uma vez que ela precisa assimilar o diagnóstico:

[...] e eu sozinha, saí do médico transtornada, transtornada, eu não sei como é que eu não batio carro. Não consegui ligar para ninguém, saí do consultório chorando, desesperada. Saí, fui para casa da minha mãe. Meu marido não estava na cidade e a primeira pessoa que eu pensei foi na minha mãe. Cheguei lá transtornada, fiquei uma meia hora soluçando, chorando desesperada, não conseguia falar, nossa foi terrível... (Tânia).

Quando o familiar está junto da mulher no momento em que esta recebe o diagnóstico, ele também fica abalado e surpreso com o resultado final. Refere que, mesmo não tendo condições de dialogar muito, acredita que sua presença serve de apoio emocional, pois ela pode se desabafar na companhia de alguém.

Foi assim... um baque... A gente também fica meio assim, sem ter muito o que falar, porque você nunca passou por essa situação, você não sabe o que dizer. Mas no que eu pude, eu ajudei. Eu acho que se ela tivesse ido sozinha, não teria um meio dela desabafar. Naquele intervalo que ela pegou o exame, conversou com o médico e na hora que saiu do consultório, eu acho que na hora a gente é um meio de apoio... (irmã de Camila).

Nesse momento, as mudanças passam a ser inseridas no contexto familiar como um todo, de forma que os anseios, medos e angústias invadem não apenas a mulher que recebeu um diagnóstico de doença grave, mas também todos os membros da família, pelo menos aqueles mais próximos, os quais se deparam com a possibilidade de perda de um ente querido.

0 momento do recebimento de um diagnóstico de câncer é acompanhado de intenso estresse psicológico, tanto para o paciente quanto para seus familiares. ${ }^{11}$ Em um estudo com pacientes oncológicos em tratamento quimioterápico por ocorrência de metástase, também foi identificado que o recebimento do diagnóstico constitui um momento ímpar na vida dos indivíduos, acompanhado de sofrimento em função de esses indivíduos estabelecerem uma relação íntima e direta com a morte. ${ }^{12}$

Assim, cabe à enfermagem estender as orientações acerca da doença e dos tratamentos, também aos membros familiares, principalmente aqueles que se mostram mais próximos, para que possam continuar sendo fonte de apoio e estímulo para a mulher continuar sua batalha contra o câncer. ${ }^{13}$ Isso porque a rede de apoio social costuma ser bastante eficiente na vivência com o câncer, pois, além de contribuir como suporte emocional, também auxilia nos cuidados diários às mulheres. ${ }^{14}$
0 desespero provocado pelo diagnóstico de câncer faz com que a mulher arremeta seus sentimentos e pensamentos em direção à família, sendo estes potencializados quando a mulher é mãe de crianças totalmente dependentes, pois a responsabilidade pelo cuidado com os filhos, culturalmente, é um mister enredado na vivência das mulheres:

[... ] eu sai de lá chorando, falei: Meu Deus, eu tenho uma filha, minha filha não tem nem um ano direito, e agora, meu Deus? Fui direto para a igreja e comecei a pedir para Deus. "Deus o que eu faço?" (Ana Maria).

Estando a mulher nessa fase da vida em que tem filhos pequenos, dependentes de seus cuidados, e deparando-se com o diagnóstico de câncer, além do desespero diante do estigma da patologia, que ela associa imediatamente com a morte, emerge o desespero em relação aos filhos e ao futuro destas, pois ela não sabe quem assumirá os cuidados e as responsabilidades que até então pertenciam a ela:

Foi desesperador a hora que o médico chegou e falou: "Deu um probleminha", e eu já perguntei: "mas que probleminha?", e ele falou que era câncer. A única coisa que eu pensei foi na minha filha [de 2 anos]. Eu falei para o médico: "Eu não quero morrer, eu quero criar a minha filha primeiro, quero que ela seja independente, que ela se forme e seja independente para depois eu morrer". Porque ela depende muito de mim, ela é muito grudada comigo. Foi a única coisa que eu pensei na hora, "a minha filha”... (Mônica).

A mulher com filhos adolescentes também vivencia inquietações quanto ao futuro destes:

[...] com criança pequena, que naquela época estava com quinze anos, eu estava preparando tudo para festa de quinze anos da minha menina. "Puxa vida!" E minha menina morre de medo da morte, eu ainda tenho mais esse problema (Maria Santa).

0 impacto de receber um diagnóstico médico de doença grave é acompanhado pelo paciente com grande ansiedade, medo e incerteza ${ }^{3}$. Além disso, vale ressaltar que o impacto psicossocial do câncer envolve três áreas: o desconforto psicológico, que engloba ansiedade, depressão e raiva; mudanças no estilo de vida por conseqüência do desconfor to físico, disfunção sexual e alterações do nível de atividade; e medo e preocupações relacionados ao prognóstico da doença, ou seja, cirurgias, mutilações, metástases e a morte. ${ }^{15}$

Estudo sobre a descoberta do câncer de mama realizado com 15 mulheres mastectomizadas pontua que, para elas, ter 
recebido o diagnóstico de câncer e ter convivido com ele foi um momento carregado de medo e incertezas. ${ }^{16} \mathrm{~A}$ sensação de estar com o câncer era sinônimo de morte, que geralmente está associado a um estigma relacionado ao diagnóstico da doença, que amedronta e abala psicológica e socialmente a vida das mulheres.

Mesmo sentindo-se abalada, a mulher tenta elaborar uma melhor maneira de contar o diagnóstico para a família, preparando-se antes de chegar em casa; ou seja, mesmo inundada de emoção, ela tem consciência de seu papel, que também é de cuidadora emocional dos seus familiares:

[...] minha amiga era secretária desse médico e era da minha igreja, aí eu saí [do consultório] e falei: "Eu posso falar com você um pouco?". Daí pedipara ela chamar uma outra amiga minha que é pastora da igreja. Conversamos. Nesse período meu marido estava me procurando, e eu estava conversando com ela... Porque eu queria chegar em casa bem, porque na realidade eu não sabia como falar para meu marido e como falar para os meus filhos, que eram adolescentes... (Alessandra).

Mesmo diante do impacto emocional de descobrir-se uma portadora de câncer e dos posicionamentos negativos de alguns médicos, as mulheres tiveram um comportamento decisivo, caminhando em direção à confirmação do diagnóstico e tiveram atitudes com vistas ao tratamento. Assim, elas não permaneceram estagnadas no tempo, buscaram mais informações e esclarecimentos sobre o diagnóstico e seu prognóstico.

Para tanto, algumas procuraram um centro de atendimento maior, porque sentiram a necessidade de ouvir uma confirmação do diagnóstico e outras opiniões relativas à doença:

Eu fui para São Paulo, fiz um exame lá; consultei outra médica especialista em linfoma, que também me tranquilizou, disse que é tranquila a doença, que tem cura, que é uma das doenças que têm mais chances de cura, praticamente $95 \%$ de chances... (Tânia).

Na busca por uma resposta concreta, Tânia também procurou conhecer pessoas que já tiveram o mesmo tipo de câncer que o seu e se encontram em bom estado de saúde. A partir desses encontros, ela começa a buscar maiores informações sobre a doença, por meio de leitura desenvolvida na área:

[...] e daí a gente começa a ver as pessoas que tiveram a mesma coisa, e aí você vê que essas pessoas estão aí e já faz anos que tiveram; quer dizer, você começa a ver o outro lado [...] mas depois que comecei a ver a coisa de perto, a conversar com os médicos e pesquisar, fui me tranquilizando... (Tânia).

Um estudo sobre a trajetória para o diagnóstico e o tratamento do câncer de mama realizado no Canadá, com 35 mulheres de vários níveis sociais, identificou que, para descobrirem o diagnóstico de câncer, as mulheres buscam informações junto aos profissionais da área da saúde, e procuram por informações sobre a doença e o tratamento. ${ }^{17}$

Os familiares também procuram realizar leituras específicas referentes ao assunto, como um recurso para melhor entendimento da doença:

[...] como tudo na vida, é uma surpresa, você vai vendo passar as fases: a cirurgia, o tratamento. Eu fui estudando sobre a doença, fui lendo, e depois vai passando o tempo, a gente vai aprendendo a conviver... (filha de Regiane).

Não obstante, a família, ${ }^{18}$ diante das situações que precisa vivenciar ao deparar-se com o câncer, utiliza os potenciais de cada um de seus membros para alcançar a estabilidade do contexto familiar.

A ânsia pela cura fez com que as mulheres, em nenhum momento, mesmo desconhecendo os tratamentos, afirmassem que não queriam ou cogitassem a possibilidade de não se tratarem; pelo contrário, mesmo desconhecendo o tratamento, buscaram força interior para enfrentá-lo:

[...] logo marcou a cirurgia maior para retirada do tumor. Então foi feita uma cirurgia e ali foram retirados todas as glândulas da axila, que estavam afetadas, e vim para casa com dreno. Fiquei uma semana com o dreno. Depois de uma semana foi retirado, comecei a fazer fisioterapia, porque a gente perde $80 \%$ da saúde do braço. Depois de um mês o médico falou: "Nósjá vamos encaminhar você para fazer quimioterapia. Você se prepara, vai cair os cabelos"; e eu falei: "Tudo bem, não tem problema nenhum" (Nair).

Todas as mulheres, diante de um primeiro diagnóstico de câncer, aderiram aos diversos tipos de tratamento prescritos, sem ao menos questionarem a possibilidade de não fazê-los. Neste sentido, podemos refletir que veem neles e atribuem a eles a esperança de vida, crendo que a morte será colocada novamente o mais distante possível.

Após o evento da descoberta do diagnóstico, elas aderiram aos diversos tipos de tratamento prescritos, os quais representam, nesse momento, a única chance de vencer 0 problema; ou seja, acreditaram na possibilidade de cura. Assim, apegam-se à esperança de alcançar a cura por meio deles. 0 
tratamento significa a possibilidade de lhes ser devolvida a longevidade, colocando a morte o mais distante possível. Isso pode ser confirmado no discurso abaixo:

[...] saiu a biópsia, me encaminharam para a médica, ela já me atendeu. Queria começar logo. Em uma semana eu já comecei o tratamento... (Tânia).

Um estudo com mulheres portadoras de câncer de mama aponta que elas aceitam as regras e as condições impostas pelos tratamentos por acreditarem que por meio deles alcançarão a cura da doença. ${ }^{19}$ Nessa nova etapa, a dos tratamentos, cabe aos profissionais de enfermagem repensar sua postura enquanto prática social e, assim, adotar atitudes que revelam a preocupação e a intencionalidade de cuidar com responsabilidade, zelo, respeito e afeto, não só para com as mulheres, mas também seus familiares que se encontram em um momento de grande fragilidade emocional. ${ }^{20}$

\section{CONCLUSÃO}

A experiência da mulher em vivenciar o câncer está acompanhada de alguns acontecimentos sequenciais, os quais sofrem modificações em virtude do significado que elas atribuem a esse novo evento. Antes da descoberta do diagnóstico de câncer, assim como ocorre em outras doenças, as pessoas vivenciam uma série de experiências que muitas vezes são desvalorizadas pelos profissionais, e, por consequência, pode ocorrer um atraso no estabelecimento do diagnóstico, o que, por sua vez, contribui para o insucesso do tratamento.

0 itinerário percorrido pelas mulheres até a descoberta do câncer é caracterizado como um tempo bastante particular na vida delas, em que dividem de maneira muito tímida suas suposições, compartilhando suas descobertas de alterações com poucas pessoas de seu convivio. Isso porque, além de existir um espaço cronológico de tempo que é único para cada ser na

\section{REFERÊNCIAS}

1-Rzeznik C, Dall'agnol CM. (Re) descobrindo a vida apesar do câncer. Rev Gauch Enferm 2000 ago; (n esp): 84-100.

2-Costa CA, Lunardi Filho WDL, Soares NV. Assistência humanizada ao cliente oncológico: reflexões junto à equipe. Rev Bras Enferm 2003 maio/jun; 56(3): 310-14.

3- Molina-Salci MA. Enfrentando o câncer em família [dissertação de mestrado]. Maringá(PR): Programa de Pós-Graduação em Enfermagem/Universidade Estadual de Maringá; 2005.

4-Marcon SS, Nogueira LA, Fonseca ARO, Uchimura TT. Características da doença crônica em famílias residentes na região norte do município de Maringá, Estado do Paraná: uma primeira aproximação. Acta Sci Health Sci 2004 jan/jun; 26(1): 83-93.

5- Oliveira MM, Monteiro ARM. Mulheres mastectomizadas: ressignificação da existência. Texto Contexto Enferm 2004 jul/set; 13(3): 401-08. busca de atendimento especializado, existe ainda, em muitos casos, uma peregrinação por parte da mulher, por vários médicos, até que a doença seja efetivamente diagnosticada.

Assim, o recebimento do diagnóstico de câncer constitui o momento em que a família começa a compartilhar da experiência da mulher de vivenciar o câncer. Esse instante, no qual todos estão diante da nova realidade, é considerado como um dos piores da vida, pois se deparam com uma avalanche de sentimentos que os colocam em um dilema perante a aceitação da doença, inserida agora no corpo da mulher e em todo 0 contexto familiar, precisando elaborar novos conceitos e se adaptar à nova realidade. Ressaltamos que o impacto emocional ocorre mesmo quando as mulheres já realizaram, em seu íntimo, suposiç̧ões negativas sobre as alterações percebidas no corpo, relacionando-as com uma doença maligna.

Nesse sentido, este estudo traz para os profissionais a possibilidade de conhecer a realidade das fases existentes anteriormente ao recebimento do diagnóstico, para que valorizem mais as queixas das pessoas no momento inicial e atuem mais rapidamente no direcionamento dos tratamentos, e garantam um maior índice de cura para as neoplasias. É sabido que, mesmo sendo o câncer uma doença com altos índices de mortalidade, se diagnosticado precocemente e tratado adequadamente, verifica-se o aumento cada vez mais surpreendente da sobrevida, do controle e, muitas vezes, da cura da doença. Esses aspectos necessitam ser ressaltados pelos profissionais ao trabalharem na prevenção e promoção da saúde, para evitar ou retardar o desenvolvimento do câncer, como também no momento em que transmitem o diagnóstico à pessoa.

Isso poderá contribuir para que seja diminuído o impacto associado ao recebimento do diagnóstico de câncer, e, além disso, essas atitudes poderão contribuir para uma mudança da concepção cultural de que o câncer apenas traz sofrimento e morte, para a de que essa doença pode ser tratada, controlada e, em muitos casos, curada.

6-Santana CJM, Lopes GT. 0 cuidado especializado do egresso da residência em enfermagem do Instituto Nacional de Câncer - INCA. Esc Anna Nery Rev Enferm 2007 set; 11(3): 417-22.

7-Glazer BG, Strauss AL. The discovery of grounded theory: strategies for qualitative research. Chicago(USA): Aldine Publishing Company; 1967.

8-Resta DG, Budó MLD. A cultura e as formas de cuidar em família na visão de pacientes e cuidadores domiciliares. Acta Sci Health Sci 2004 jan/jun; 26(1): 53-60.

9-Ospina MDE, Soto ACP. Entre el rito y rutina: el rol de cuidadoras em lãs mujeres de Medellín. Invest Educ Enferm 2001 sep/dez; 19(2): 58-65.

10-González JS. Estructuras sociales, división sexual del trabajo y enfoques metodológicos. La estructura familiar y la función sociosanitaria de la mujer. Invest Educ Enferm 2007 jan/jun; 25(1): 66-73. 
11-Kissane DW. Psychiatric disorder in women with early stage and advanced breast câncer: a comparative analysis. Aust N Z J Psychiatry 2004 May; 38(5): 320-26.

12-Trincaus MR. A morte em seu mostrar-se ao paciente oncológico em situação de metástase [dissertação de mestrado]. Ribeirão Preto (SP): Escola de Enfermagem de Ribeirão Preto/ EERP-USP; 2005.

13-Souto MD, Souza IEO. Sexualidade da mulher após a mastectomia. Esc Anna Nery Rev Enferm. 2004 dez; 8(3): 402-10.

14-Coyne E, Borbasi S. Holding it all together: breast cancer and its impact on life for younger women. Contemp Nurse. 2007 jan/mar; 23(2): 157-69.

15-Camargo TC, Souza IE. 0. Acompanhando mulheres que enfrentam a quimioterapia para o câncer de mama: uma compreensão das singularidades. Esc Anna Nery Rev Enferm 2002 ago; 6(2): 261-72.

16- Pinho LS, Campos ACS, Fernades AFC, Lobo AS. Câncer de mama: da descoberta à recorrência da doença. Rev Eletr Enferm [on- line]
2007 [citada 26 jan 2008] jan/abr; 9(1): 154-65. Disponível em: http://www.fen.ufg.br/revista/v9/n1/v9n1a12.htm

17- Angus J, Paszar L, Mckeever P, Trebilcock A, Shivji F, Edwards B. Pathways to breast cancer diagnosis and treatment: exploring the social relations of diagnostic delay. Texto Contexto Enferm 2007 out/ dez; 16(14): 591-98.

18- Biffi RG. A dinâmica familiar de um grupo de mulheres com câncer de mama [tese de doutorado]. Ribeirão Preto (SP): Escola de Enfermagem de Ribeirão Preto/EERP-USP; 2003.

19- Bergamasco RB, Angelo M. 0 sofrimento de descobrir-se com câncer de mama: como o diagnóstico é experienciado pela mulher. Rev Bras Cancerol 2001 jul/ago/set; 47(3): 277-82.

20-Moura ACF, Moreira MC. A unidade de quimioterapia na perspectiva dos clientes - indicativos para gestão do ambiente na enfermagem oncológica. Esc Anna Nery Rev Enferm 2005 dez; 9(3): 372-80.

\section{Nota}

a Parte da Dissertação de Mestrado: ENFRENTANDO 0 CÂNCER EM FAMíLIA. Apresentado ao Programa de pós-graduação - Mestrado em Enfermagem da Universidade Estadual de Maringá-PR, em dezembro de 2005. 